\title{
Personalia
}

\section{Prof. O. Haempel zum Gedächtnis}

Am 2. Januar 1953 verschied nach kurzem schweren Leiden der bekannte österreichische Fischereibiologe Prof. Dr. OsKar HaEMPEL im 71. Lebensjahre.

Er war ein Schüler des Altmeisters der Fischereibiologie Prof. HoFER, als dessen Assistent er nach Vollendung seiner Studien an der Bayrischen Biologischen Versuchsanstalt in München tätig war. Von hier ging er dann nach Wien, wo er sich 1909 an der Hochschule für Bodenkultur als Privatdozent für das Fach Hydrobiologie und Fischereiwirtschaft habilitierte. Im Jahre 1920 erfolgte gleichzeitig met der Verleihung des Titels eines ausserordentlichen Professors seine Berufung an die neugegründete Lehrkanzel für Hydrobiologie an dieser Hochschule. 1928 übernahm er noch die Leitung der vom ihm begründeten Fischereibiologischen Bundesanstalt in Weissenbach am Attersee.

Von seinen zahlreichen Veröffentlichungen aus nahezu allen Gebieten der Hydrobiologie und Fischereiwirtschaft sind die bekanntesten der „Leitfaden der Biologie der Fische” (1912), das „Handbuch der Fischereibetriebslehre" gemeinsam mit DoLjaN (1921) und die „Biologie der Alpenseen” (1930).

In den letzten Jahren befasste er sich besonders mit dem Studium der Wirkung von Hormonen auf Fische und war noch in seinen letzten Lebenstagen auf diesem Gebiete forschend tätig.

Nicht nur den Forscher HAEMPEL werden alle, die ihn kannten, in ehrenvollem Andenken behalten sondern ebenso den stets hilfsbereiten und verständnisvollen Berater und Freund.

K. STUNDL 